\title{
Phenotypic and genetic relationships of bovine natural antibodies binding keyhole limpet hemocyanin in plasma and milk
}

\author{
B. de Klerk, ${ }^{* 1}$ B. J. Ducro, ${ }^{*}$ H. C. M. Heuven, ${ }^{*} \dagger$ I. den Uyl,‡ J. A. M. van Arendonk, ${ }^{*}$ H. K. Parmentier,§ \\ and J. J. van der Poel* \\ *Animal Breeding and Genomics Centre, Wageningen University, PO Box 338, Wageningen, the Netherlands \\ †Faculty of Veterinary Medicine, Utrecht University, PO Box 80125, Utrecht, the Netherlands \\ $\ddagger$ Animal Health Services, PO Box 9, Deventer, the Netherlands \\ $\S$ Adaptation and Physiology Group, Wageningen University, PO Box 338193, Wageningen, the Netherlands
}

\begin{abstract}
To improve the health status (resilience) of dairy cows, levels of natural antibodies (NAb) might be useful. The objective of the present study was to compare levels and to estimate genetic parameters for NAb measured in milk and plasma samples. Titers of NAb IgM and $\operatorname{IgG}$ isotype-binding keyhole limpet hemocyanin of 2,919 cows, in both plasma and milk, were measured using ELISA. Analysis revealed that NAb levels in milk significantly increased with parity, whereas they remained constant in plasma. Moderate positive phenotypic correlations were found between NAb levels in milk and in plasma: 0.18 for IgG and 0.40 for IgM. This indicates that $\mathrm{NAb}$ from milk and plasma might reflect different aspects of dairy cow health status. However, high genetic correlations were found for NAb in milk and plasma: 0.81 for IgG and 0.79 for IgM. Heritabilities (SE in parentheses) for NAb measured in plasma [0.15 (0.05) for IgG and 0.25 (0.06) for IgM] were higher than heritabilities of NAb measured in milk [0.08 (0.03) for IgG and $0.23(0.05)$ for IgM]. Our results indicate that NAb measured in milk and plasma are heritable and likely have a common genetic background, suggesting that NAb levels measured in milk might be useful for genetic improvement of disease resistance.
\end{abstract}

Key words: dairy cattle, natural antibody, genetic parameter

\section{INTRODUCTION}

Genetic selection for improved disease has become more important because of the limitation of usage of antibiotics. Selection for animal health status is a challenging task due to the lack of reliable, cheap, and easy to measure parameters. Natural antibodies (NAb) might be a novel parameter that enables selection of

Received September 4, 2014.

Accepted December 22, 2014

${ }^{1}$ Corresponding author: Britt.deklerk@wur.nl cows with an improved ability to stay healthy and to remain productive over a longer period.

In mammals, NAb represent an important component of innate immunity, forming a first line of defense and linking innate and specific immunity (Ochsenbein and Zinkernagel, 2000). Natural antibodies are defined as immunoglobulins derived from self-renewing CD5+ B-1 cells (Casali and Notkins, 1989; Baumgarth et al., 2005). They have been found in all animals tested so far without intentional antigenic stimulation (Avrameas, 1991; Ochsenbein and Zinkernagel, 2000) and have been proposed to reflect the ability of an animal to stay healthy and prolong survival (Boes, 2000; Star et al., 2007).

Natural antibodies are suggested to play an essential role in induction of a primary immune response and improve immune responsiveness to protect individuals against viral and bacterial pathogens (Thornton et al., 1994; Ochsenbein et al., 1999; Kohler et al., 2003; Lammers et al., 2004). In chicken, NAb-binding keyhole limpet hemocyanin (KLH) was indicative for a higher probability of survival during the laying period (Star et al., 2007; Sun et al., 2011). In cattle, NAb were found in both plasma and milk (van Knegsel et al., 2007; Ploegaert et al., 2011) and NAb levels increased with age (Srinivasan et al., 1999; van Knegsel et al., 2007). A positive phenotypic relationship was suggested in dairy cattle between NAb measured in plasma and their energy balance, milk yield, and DMI (van Knegsel et al., 2007). However, in milk, negative relations were found between NAb levels and energy balance, milk yield, and DMI (van Knegsel et al., 2007). Furthermore, Ploegaert (2010) suggested that NAb (especially isotype IgG1) protect against clinical mastitis and high SCC. Heritabilities of KLH-binding NAb levels measured in plasma were 0.18 for IgM and 0.32 for IgG (Thompson-Crispi et al., 2013). Heritabilities of KLH NAb measured in milk were 0.32 for IgG and 0.41 for IgM (Wijga et al., 2013). Together these results show that NAb give information on the health perspective of animals and might also be used for genetic selection to improve health traits. 
Measurement of NAb levels in milk, rather than in plasma, is noninvasive and cheap. Natural antibodies measured in milk may thus be a promising parameter reflecting innate immunity, which might be predictive for disease resistance of dairy cows. As a first step in determining the value of NAb measured in milk as a parameter of disease resistance, phenotypic and genetic relationships of NAb measured in plasma and milk is useful. Knowledge of this relationship is currently lacking. The objective of our study was to estimate phenotypic and genetic parameters for NAb measured in plasma and milk. Genetic parameters will reveal whether NAb levels in plasma and in milk reflect the same trait.

\section{MATERIALS AND METHODS}

\section{Animals and Samples}

Data used are from the Dutch project WeerbaarVee (resilient livestock). In February and March 2011, plasma and milk samples of 3,034 dairy cows were simultaneously collected from 29 Dutch dairy farms spread over the country. Animals with an unknown ID number or with missing values were excluded from the data set; thus, 2,919 cows were used for the final analyses. To ensure that the results would be representative of future farming conditions, farms were required to have at least 60 cows in milk recording and farms with a mean production level in the lowest quartile were excluded. The farms were chosen from the group of farms with either a high herd age (mean $=4.73 \mathrm{yrs}$; farm type 1 ) or an average herd age (mean $=4.16 \mathrm{yrs}$; farm type 2) in the year before the start of the study. All selected farms needed to participate in the national milk production registration system (MPR) and were required to agree to sampling of plasma and milk from cows and detailed disease recording. Most $(72.5 \%)$ of the cows included in the study were purebred Holstein Friesians. Furthermore, preliminary results showed no significant effect of breed and it was therefore left out for further analyses. Milk samples were collected in conjunction with MPR from all lactating cows. Plasma samples were taken from about 70 cows per farm: both lactating and nonlactating (dry cows and heifers before calving). The aim of the data set was to keep the distribution of cows over different parities and lactation stage as equal as possible; therefore, cows were selected for plasma sampling based on their parity and lactation stage. Clinically sick animals were not included in MPR and therefore have no milk samples. In total 2,610 milk samples and 2,032 plasma samples were collected. The pedigree file for estimating genetic parameters was provided by CRV (Cooperative Cattle Improvement Organization, Arnhem, the Netherlands), and included 30,436 animals. Cows used within this study originated from 994 sires and 2,367 dams.

\section{$N A b$}

Natural antibody isotypes $\operatorname{IgM}$ and $\operatorname{IgG}$ binding Megathura crenulata-derived KLH were determined in individual plasma and milk samples by an indirect 2-step ELISA. Flat-bottomed 96-well medium binding plates were coated overnight at $4^{\circ} \mathrm{C}$ with $1 \mu \mathrm{g} / \mathrm{mL}$ of KLH (MP Biomedicals Inc., Aurora, Ohio), $100 \mu \mathrm{L} /$ well, in coating buffer $\left(5.3 \mathrm{~g} / \mathrm{L}\right.$ of $\mathrm{Na}_{2} \mathrm{CO}_{3}$ and $4.2 \mathrm{~g} / \mathrm{L}$ of $\mathrm{NaHCO}_{3}$, pH 9.6). After washing, plasma and milk samples were diluted in 4 steps with a dilution buffer (PBS; $10.26 \mathrm{~g} / \mathrm{L}$ of $\mathrm{Na}_{2} \mathrm{HPO}_{4} \cdot \mathrm{H}_{2} \mathrm{O}, 2.36 \mathrm{~g} / \mathrm{L}$ of $\mathrm{KH}_{2} \mathrm{PO}_{4}$, and $4.50 \mathrm{~g} / \mathrm{L}$ of NaCl, pH 7.2, containing $0.05 \%$ Tween 20 and $0.5 \%$ normal horse serum). Plates were incubated for $1.5 \mathrm{~h}$ at room temperature with the samples 1:3 diluted (1:30, 1:90, 1:270, and 1:810). Binding of the antibodies to KLH was visualized using a 1:20,000 diluted rabbit anti-bovine IgGFc labeled with peroxidase $(\mathrm{RABo} / \mathrm{IgGFc} /$ peroxidase, Nordic, Tilburg, the Netherlands) and 1:20,000 diluted rabbit anti-bovine $\operatorname{IgM}(\mathrm{RAB} / \mathrm{IgM} /$ peroxidase, Nordic). After washing, substrate (tetramethylbenzidine and $0.05 \% \mathrm{H}_{2} \mathrm{O}_{2}$ ) was added. After $10 \mathrm{~min}$, the reaction was stopped with 2.5 $N \mathrm{H}_{2} \mathrm{SO}_{4}$. Extinctions were measured with a Multiskan (Labsystems, Helsinki, Finland) at a wavelength of 450 $\mathrm{nm}$. Antibody levels (titers) were expressed as log2 values of the highest dilutions giving an extinction closest to $50 \%$ of EMAX, where EMAX represents the highest mean extinction of a standard positive reaction present on each flat-bottomed ELISA-plate (Ploegaert et al., 2010b). The EMAX was calculated based on a plasmacalibrated line for each ELISA plate, for both milk and plasma samples. An amount of 3 titer units was added to all obtained NAb titers to create positive values.

\section{Statistical Analyses}

Descriptive statistics were calculated using SAS (version 9.2). Variance components for levels of different $\mathrm{NAb}$ isotypes in milk and plasma samples were estimated with a linear animal model:

$$
\begin{aligned}
\mathrm{Y}_{\mathrm{ijklm}}=\mu & +\mathrm{PAR}_{\mathrm{i}}+\mathrm{LAC}_{\mathrm{j}}+\mathrm{HERD}_{\mathrm{k}} \\
& +\operatorname{animal}_{1}+\mathrm{e}_{\mathrm{ijkl}},
\end{aligned}
$$

where $\mathrm{Y}$ was NAb levels (i.e., M-IgG = IgG in milk, $\mathrm{M}-\operatorname{IgM}=\operatorname{IgM}$ in milk, $\mathrm{P}-\operatorname{IgG}=\operatorname{IgG}$ in plasma and $\mathrm{P}$ - 
Table 1. Numbers, means, and standard deviations (SD) for titers of natural antibody isotypes (IgG and IgM) measured in both milk (M) and plasma $(\mathrm{P})$ samples

\begin{tabular}{lcrl}
\hline Antibody & No. & Mean & SD \\
\hline M-IgG & 2,610 & 3.25 & 0.83 \\
M-IgM & 2,610 & 5.60 & 1.07 \\
P-IgG & 2,032 & 8.03 & 1.24 \\
P-IgM & 2,032 & 11.56 & 0.88 \\
\hline
\end{tabular}

$\operatorname{IgM}=\operatorname{IgM}$ in plasma), $\mu$ is the population mean, PAR is fixed effect of parity ( $\mathrm{i}=$ class of parities, where $1=$ heifers before first calving, $2=$ parity $1,3=$ parity 2 , $4=$ parity 3 , and $5=$ parity $\geq 4$ ), LAC is fixed effect of lactation stage (where $1=<60$ DIM, $2=60-120$ DIM, $3=120-200$ DIM, $4=200-305$ DIM, $5=>305$ DIM, and $6=$ nonlactating cows), HERD is random herd effect, animal is random additive genetic effect of the cow, and e is the random residual. Genetic analyses were performed with ASREML software (version 3.0, Gilmour et al., 2009). The estimated variance components from single trait analysis were used to estimate heritabilities. Additionally, phenotypic and additive genetic correlations were calculated from variance components obtained by bivariate analysis.

\section{RESULTS}

\section{Descriptive Statistics}

Preliminarily analysis of the data revealed that all NAb titers were normally distributed. Means and standard deviations of all 4 NAb-binding KLH (IgM and IgG in both plasma and milk) are shown in Table 1. Mean levels of both IgG and IgM in milk were lower than those detected in plasma. The trait with most variation was $\operatorname{IgG}$ in plasma.

In total, 29 farms participated in our study, ranging between 53 and 189 lactating cows per farm, with a mean of 89 lactating cows. Mean herd age of productive cows on farms participating in the study was 4.8 (4.3-6.0) yr. Generally farms classified as high had lower NAb levels than farms classified as average for both NAb levels in milk and plasma. Nevertheless, no significant differences in NAb levels were found between these 2 groups. Farm-type was therefore not included in further analyses.

The cows in our study $(\mathrm{n}=2,919)$ had a mean parity of 2.74 (maximum $=14$ ) and were on average 205 DIM $(\max =877)$. Plasma samples were taken from 3 groups: lactating cows, dry cows, and pregnant heifers. Higher NAb levels in milk and blood were detected in dry compared with lactating cows (Table 2). We found that parity significantly $(P<0.001)$ affected NAb levels in milk; overall, NAb levels in milk increased with parity (Table 2). Natural antibody levels in plasma were not significantly influenced by parity (Table 2 ). The IgM levels in milk significantly decreased after the first lactation stage and significantly increased again toward the end of the lactation period. The same patterns for lactation stages were also observed for IgG, except between the first 3 lactation stages, no significant differences were found. Natural antibody levels in plasma only slightly raised with increasing lactation stage (Table 2).

\section{Genetic and Phenotypic Parameters}

Estimates for variance components and heritabilities were obtained from a linear animal model and are

Table 2. Corrected means (LSMEANS) for natural antibody levels (IgG and IgM) in milk (M) and plasma (P) for different parities (PAR class) and different lactation stages (LAC class)

\begin{tabular}{llcccc}
\hline Item & Number & M-IgG & M-IgM & P-IgG & P-IgM \\
\hline LAC class $^{1}$ & 1 & $3.11^{\mathrm{a}}$ & $5.39^{\mathrm{a}}$ & $7.96^{\mathrm{a}}$ & $11.36^{\mathrm{a}}$ \\
& 2 & $3.04^{\mathrm{a}}$ & $5.14^{\mathrm{b}}$ & $8.25^{\mathrm{a}}$ & $11.61^{\mathrm{b}}$ \\
& 3 & $3.11^{\mathrm{a}}$ & $5.31^{\mathrm{a}}$ & $8.17^{\mathrm{a}}$ & $11.48^{\mathrm{ab}}$ \\
& 4 & $3.31^{\mathrm{b}}$ & $5.81^{\mathrm{c}}$ & $8.09^{\mathrm{a}}$ & $11.55^{\mathrm{ab}}$ \\
& 5 & $3.59^{\mathrm{bc}}$ & $6.30^{\mathrm{d}}$ & $8.09^{\mathrm{a}}$ & $11.62^{\mathrm{b}}$ \\
PA class $^{2}$ & 6 (dry cows) & - & - & $8.25^{\mathrm{a}}$ & $11.99^{\mathrm{c}}$ \\
& 1 (heifers before calving) & - & - & $8.58^{\mathrm{a}}$ & $11.60^{\mathrm{a}}$ \\
& 2 & $3.29^{\mathrm{a}}$ & $5.52^{\mathrm{a}}$ & $8.08^{\mathrm{a}}$ & $11.56^{\mathrm{a}}$ \\
& 3 & $3.33^{\mathrm{ac}}$ & $5.78^{\mathrm{b}}$ & $7.93^{\mathrm{ab}}$ & $11.67^{\mathrm{a}}$ \\
& 4 & $3.41^{\mathrm{bc}}$ & $5.99^{\mathrm{c}}$ & $7.91^{\mathrm{ab}}$ & $11.62^{\mathrm{a}}$ \\
& 5 & $3.45^{\mathrm{b}}$ & $5.96^{\mathrm{c}}$ & $7.77^{\mathrm{b}}$ & $11.51^{\mathrm{a}}$ \\
\hline
\end{tabular}

${ }^{a-d}$ Least squares means that do not share a superscript are significantly different $(P<0.05)$.

${ }^{1}$ Lactation stage classes $1-6$, where $1=<60$ DIM, $2=60-120$ DIM, $3=120-200$ DIM, $4=200-305$ DIM, 5 $=>305$ DIM, and $6=$ nonlactating cows.

${ }^{2}$ Parity classes $1-5$, where $1=$ heifers before first calving, $2=$ parity $1,3=$ parity $2,4=$ parity 3 , and $5=$ parity $\geq 4$. 
Table 3. Estimates and corresponding standard errors of variance components and heritability of natural antibody isotypes IgG and IgM in milk $(\mathrm{M})$ and plasma $(\mathrm{P})^{1}$

\begin{tabular}{lccc}
\hline Antibody & $\sigma_{a}^{2}$ & $\sigma_{h}^{2}$ & $h^{2}(\mathrm{SE})$ \\
\hline M-IgG & 0.05 & 0.07 & $0.08(0.03)$ \\
M-IgM & 0.22 & 0.04 & $0.23(0.05)$ \\
P-IgG & 0.22 & 0.15 & $0.15(0.05)$ \\
P-IgM & 0.19 & 0.07 & $0.25(0.06)$ \\
\hline
\end{tabular}

${ }^{1}$ Where $h^{2}=\sigma_{a}^{2} / \sigma_{p}^{2}, \sigma_{p}^{2}$ is the phenotypic variance $\left(\sigma_{a}^{2}+\sigma_{h}^{2}+\sigma_{e}^{2}\right), \sigma_{a}^{2}$ is the additive genetic variance, $\sigma_{e}^{2}$ is the environmental variance, and $\sigma_{h}^{2}$ is the herd variance.

presented in Table 3. Heritability estimates ranged between $0.08(\mathrm{SE}=0.03)$ and $0.25(\mathrm{SE}=0.06)$. The IgM-binding KLH had higher heritability estimates for both milk and plasma (0.23 and 0.25) compared with IgG-binding KLH (0.08 and 0.15). Heritabilities of NAb levels were higher in plasma for both IgG and IgM $(0.15$ and 0.25$)$ than in milk (0.08 and 0.23). Positive phenotypic and genetic correlations between NAb levels measured in plasma and milk for both IgG and IgM (Table 4) were observed. Phenotypic correlations between the same isotype in plasma and milk were moderate for both IgM- and IgG-binding KLH (0.40 and 0.18 respectively). Genetic correlations were higher than phenotypic correlations. We found high positive genetic correlations between the same isotypes in plasma and milk (0.79 for IgM and 0.81 for $\operatorname{Ig} G$ ).

\section{DISCUSSION}

The aim of our study was to provide greater insight on the levels of NAb isotypes binding KLH collected on the same day in both plasma and milk. A genetic analysis was performed on NAb levels in a large group of cows. Genetic and phenotypic correlations were estimated between $\mathrm{NAb}$ levels measured in plasma and milk.

\section{Use of Samples}

Different isotypes of NAb can be measured. A large proportion of $\mathrm{NAb}$ in circulation are expected to be of the IgM isotype. Therefore, in our study, the IgM isotype was studied. In addition to IgM, IgG was also chosen, as these 2 isotypes differ from each other in both physiological function and structure. Immunoglobulin $\mathrm{G}$ has a monomeric structure, whereas IgM has a pentameric structure. Isotype IgM is polyreactive and more involved in early, innate immune responses, whereas IgG plays a role in the adaptive response (Schroeder and Cavacini, 2010). Therefore analyzing these 2 isotypes is expected to provide more insight in potential differences in NAb levels in plasma and milk. Although IgA can be found in milk, the levels of IgA in plasma were below the detection limit of the assay used for our study, and were therefore not included in present analysis.

In the present study, NAb-binding KLH were used. Other studies on NAb in dairy cows included $\mathrm{NAb}$ binding innate antigens such as LPS, lipoteichoic acid, and peptidoglycan (van Knegsel et al., 2007; Ploegaert et al., 2010b, 2011; Wijga et al., 2013). These other antigens are present on bacteria common in the environment of most dairy cows; KLH, on the other hand, is likely not present in the environment. Exposure to the innate antigens before sampling cannot be excluded, which may complicate comparison of our results with results from other research with other antigens.

Natural antibody levels are influenced by different environmental factors. In the present study, mean $\mathrm{NAb}$ levels varied between farms. This is in accordance with earlier studies (Ploegaert et al., 2010b; Wijga et al., 2013). This may be because of housing facilities, farm management, and feeding, or genetic factors resulting from differences in breeding decisions over time.

In the present study, no specific groups of animals were chosen. Within other studies, such as Ploegaert et al. (2011), only cows with low SCC were used; Ploegaert et al. (2010b) and Wijga et al. (2013) only used first-parity cows. Our analysis revealed a clear effect of parity on levels of NAb-binding KLH in milk, which confirms earlier findings in dairy cows by van Knegsel et al. (2007). This implies that also the age composition of a group of cows should be considered when comparing genetic parameters between studies. This could be explained by the fact that younger ani-

Table 4. Phenotypic (above diagonal) and genetic (below diagonal) correlations (SE in parentheses), between IgG and IgM measured in plasma (P) and milk (M)

\begin{tabular}{|c|c|c|c|c|}
\hline Item & M-IgM & M-IgG & P-IgM & P-IgG \\
\hline M-IgM & - & $0.48(0.06)$ & $0.40(0.05)$ & $0.16(0.04)$ \\
\hline M-IgG & $0.64(0.17)$ & - & $0.13(0.04)$ & $0.18(0.02)$ \\
\hline P-IgM & $0.79(0.09)$ & $0.14(0.23)$ & & $0.34(0.04)$ \\
\hline P-IgG & $0.29(0.20)$ & $0.81(0.18)$ & $0.09(0.20)$ & 一 \\
\hline
\end{tabular}


mals are less exposed to exogenous stimuli than older animals. For example, heritabilities might be lower in a more diverse group of animals, with respect to age, due to more environmental variation. However, other studies in poultry (Berghof et al., 2010) and mammals showed that NAb levels do not only depend on exogenous stimuli, but are also related to autoantigens (Cheng and Chamley, 2008).

\section{Phenotypic Parameters of NAb Levels in Milk and Plasma}

The pentameric structure of IgM results in a higher binding (avidity) to antigens than $\mathrm{IgG}$, which has a monomeric structure. Second, IgM is more abundantly present in the body of vertebrates than IgG (Ehrenstein and Notley, 2010). Immunoglobulin M is the first antibody isotype that is produced by $\mathrm{B}$ cells. In reaction to antigenic challenge, IgM-producing B-cells can switch to B-cells producing other isotypes under the influence of activated by T-cells (Market and Papavasiliou, 2003). In the present study, levels of IgG-binding KLH showed more variation than IgM in plasma (Table 1). The IgG levels are likely to be more affected by environmental exposure to bacteria and other antigens. Wijga et al. (2013) and Thompson-Crispi et al. (2013) found similar results in milk and plasma, respectively.

The present findings showed that NAb levels were lower in milk than in plasma, which is in agreement with earlier studies (Ploegaert et al., 2011; van Knegsel et al., 2007). The NAb isotypes IgM and IgG may both be transported from plasma to milk (Kacskovics et al., 2000; Östensson and Lun, 2008) in varying degrees depending on stage of lactation, colostrogenesis, and also in response to inflammation in the mammary gland. Phenotypic correlations between NAb levels measured in plasma and milk were moderately positive (Table 4), which means that these correlations are not close to one and are lower than genetic correlations. This could be due to noise in measurements, but also might indicate that NAb measured in milk and plasma might reveal different information regarding the health status of a cow. This finding suggests that phenotypically NAb levels in milk do not perfectly mirror NAb levels in plasma. The positive and high genetic correlations found in our study (Table 4) support a common background of NAb levels in milk and plasma. In an earlier study on 17 cows (different parities and lactation stages, but only cows with a low SCC), a higher positive phenotypic correlation (0.69) was found between the average of 10 individual measurements of total NAb levels binding KLH in milk and plasma (Ploegaert et al., 2011). Using an average rather than single observation reduces the effect of measurement errors and consequently will lead to higher correlations. In contrast to our results, van Knegsel et al. (2007) found a small but negative phenotypic correlation between NAb levels in plasma and milk (-0.10). In the latter study, only 76 first-parity cows during early lactation were used. We showed that cows during first stages of lactation have different NAb levels than in later stages of lactation. Such differences in results may rest not only in number of cows but also on distribution over stage of lactation and parity.

\section{Genetic Background of NAb Levels in Milk and Plasma}

High positive genetic correlations between level of $\mathrm{NAb}$ binding KLH measured in plasma and milk for both IgG and IgM were found (0.79 and 0.81 respectively). This suggests that IgM and IgG measured in plasma and milk are regulated by the same (group of) genes. To our knowledge, no other studies published genetic correlations between NAb levels in plasma and milk. Additionally, we found a moderately positive (0.48) genetic correlation between IgG- and IgMbinding KLH measured in milk. Wijga et al. (2013) found a small but negative genetic correlation between IgM- and IgG-binding KLH $(-0.10)$ in milk. Thompson-Crispi et al. (2013) found a negative genetic correlation (-0.41) between IgM- and IgG-binding KLH in plasma, whereas in the present study a small but positive genetic correlation for both isotypes binding KLH was found.

The present study confirmed that a substantial part of variation between cows of NAb levels binding KLH in both milk and plasma is heritable (Table 3). Heritabilities of IgM- and IgG-binding KLH in milk and plasma were estimated to be between 0.08 and 0.25 . Heritabilities of NAb levels in plasma were higher than heritabilities of NAb levels in milk (Table 3). Immunoglobulin $\mathrm{M}$ had higher heritabilities for both milk and plasma. This is in agreement with findings of Wijga et al. (2013), who also found the higher heritability (across herd) for $\operatorname{IgM}(0.41, \mathrm{SE}=0.09)$ and a lower heritability for IgG-binding $\mathrm{KLH}(0.32, \mathrm{SE}=0.08)$ in milk. Higher estimates of heritabilities for IgM might be explained by the fact that IgM is naturally present and more responsible for the first line defense regardless of environmental factors (Kohler et al., 2003; Ehrenstein and Notley, 2010), where IgG is more influenced by environmental factors, which therefore could explain the lower heritabilities for IgG. However, the heritabilities of Wijga et al. (2013) are almost doubled, which can be explained by the use of different data sets. Wijga et al. (2013) used 1,695 first parity cows from 380 farms 
sired by 100 bulls. Additionally, only cows off at least 87.5\% Holstein Friesian were included. Therefore, cows will have less genetic variation what may cause differences compared with present results. Ploegaert et al. (2010b) found higher heritabilities of NAb-binding KLH in milk [0.36 (across herds) and 0.42 (intra herd)], but no distinction was made between NAb isotypes. Thompson-Crispi et al. (2013) found a higher heritability for $\operatorname{IgG}(0.32)$ than the heritability of $\operatorname{IgM}(0.18)$, both binding KLH in plasma, which is opposite to current findings. In the study of Thompson-Crispi et al. (2013), however, cows were immunized with hen egg white lysozyme before sampling, which is known to stimulate the antibody-mediated immune response. Therefore, this immunization of cows makes it hard to compare their results to our study, which is directed to naturally present antibodies binding KLH.

From our findings, we can conclude that NAb in both milk and plasma share a common genetic background and show potential for genetic selection. Selection of cows based on NAb levels measured in milk will also lead to correlated response of NAb in plasma. Measurements of NAb levels in milk are less invasive and cheaper than measurements in plasma. Measurement of $\mathrm{NAb}$ levels in milk is a more feasible option for genetic evaluation of sires based on a high number of offspring. The value of selection on parameters for NAb depends on its relationship with cow health status and longevity of dairy cows, which is currently being investigated.

\section{CONCLUSIONS}

Simultaneously measured NAb levels in both plasma and milk showed high positive genetic correlations for both IgM- and IgG-binding KLH. This indicates that they are regulated by the same set of gene(s). However, phenotypically, NAb levels might give different information on different aspects of a cow's immune status, inferred from to lower phenotypic correlations. Natural antibody isotypes IgG- and IgM-binding KLH in both plasma and milk are heritable, where IgM is more heritable than IgG. Our results indicate that NAb may be valuable for designing breeding strategies for improved health or resilience in cows. Information on NAb as selection tool can be obtained from milk samples, as genotypic correlations with NAb measured in plasma are high. Further studies are in progress to unravel the relations between NAb levels and diseases and to acquire detailed information on reasons for variability in $\mathrm{NAb}$ levels influenced by factors such as farm management, genetic background, and functional differences between milk and plasma NAb.

\section{ACKNOWLEDGMENTS}

This study is part of a joint project WeerbaarVee, which is funded by the Dutch Ministry Economic Affairs (The Hague, the Netherlands), Productschap Zuivel (Dutch Dairy Product Board, Zoetermeer, the Netherlands), CRV (Arnhem, the Netherlands), LTONoord Fondsen (Zwolle, the Netherlands), Animal Health Services (Deventer, the Netherlands), and Wageningen University (Wageningen, the Netherlands). The authors also thank all the herd owners for their collaboration and help with collecting data.

\section{REFERENCES}

Avrameas, S. 1991. Natural autoantibodies: From horror autotoxicus to gnothu seauton. Immunol. Today 12:154-159.

Baumgarth, N., J. W. Tung, and L. A. Herzenberg. 2005. Inherent specifities in natural antibodies: A key to immune defence against pathogen invasion. Springer Semin. Immunopathol. 26:347-362.

Berghof, T. V. L., G. De Vries Reilingh, M. G. B. Nieuwland, and H. K. Parmentier. 2010. Effect of aging and repeated intratracheal challenge on levels of cryptic and overt natural antibodies in poultry. Poult. Sci. 89:227-235.

Boes, M. 2000. Role of natural and immune IgM antibodies in immune responses. Mol. Immunol. 37:1141-1149.

Casali, P., and A. L. Notkins. 1989. CD5+ B lymphocytes, polyreactive antibodies and the human B-cell repertoire. Immunol. Today $10: 364-368$.

Cheng, H. M., and L. Chamley. 2008. Cryptic natural antibodies and co-potentiators. Autoimmun. Rev. 7:431-434.

Ehrenstein, M. R., and C. A. Notley. 2010. The importance of natural IgM: Scavenger, protector and regulator. Nat. Rev. Immunol. 10:778-786.

Gilmour, A. R., B. R. Cullis, and R. Thompson. 2009. ASREML User Guide. Release 3.0. VSN International Ltd., Hemel Hempstead, UK.

Kacskovics, I., Z. Wu, N. E. Simister, L. V. Frenyó, and L. Hammerström. 2000. Cloning and characterization of the bovine MHC class I-like Fc receptor. J. Immunol. 164:1889-1897.

Kohler, H., J. Bayry, A. Nicoletti, and S. V. Kaveri. 2003. Natural antibodies as tools to predict the outcome of immune response? Scand. J. Immunol. 58:285-289.

Lammers, A., M. E. V. Klomp, M. G. B. Nieuwland, H. F. J. Savelkoul, and H. K. Parmentier. 2004. Adoptive transfer of natural antibodies to non-immunized chickens affects subsequent antigenspecific humoral and cellular immune responses. Dev. Comp. Immunol. 28:51-60.

Market, E., and F. N. Papavasiliou. 2003. V(D)J Recombination and the evolution of the adaptive immune system. PLoS Biol. 1:E16.

Ochsenbein, A. F., T. Fehr, C. Lutz, M. Suter, F. Brombacher, H Hengartner, and R. M. Zinkernagel. 1999. Control of early viral and bacterial distribution and disease by natural antibodies. Science 286:2156-2159.

Ochsenbein, A. F., and R. M. Zinkernagel. 2000. Natural antibodies and complement link innate and acquired immunity. Immunol. Today 21:624-630.

Östensson, K., and S. Lun. 2008. Transfer of immunoglobulins through the mammary endothelium and epithelium and in the local lymph node of cows during the initial response after intramammary challenge with E. coli endotoxin. Acta Vet. Scand. 50:26.

Ploegaert, T. C. W. 2010. Relation of natural antibodies with risk for mastitis and high somatic cell count in Dutch Holstein Friesian cows. Pages 82-92 in Parameters for Natural Resistance in Bovine Milk (Phd Thesis). Wageningen University, Wageningen, the Netherlands. 
Ploegaert, T. C. W., E. Tijhaar, T. J. G. M. Lam, A. Taverne-Thiele, J. J. van der Poel, J. A. M. van Arendonk, H. F. J. Savelkoul, and H. K. Parmentier. 2011. Natural antibodies in bovine milk and plasma plasma: Variability among cows, repeatability within cows, and relation between milk and plasma titers. Vet. Immunol. Immunopathol. 144:88-94.

Ploegaert, T. C. W., S. Wijga, E. Tijhaar, J. J. van der Poel, T. J. G. M. Lam, H. F. J. Savelkoul, H. K. Parmentier, and J. A. M. van Arendonk. 2010. Genetic variation of natural antibodies in milk of Dutch Holstein-Friesian cows. J. Dairy Sci. 93:5467-5473.

Schroeder, H. W., and L. Cavacini. 2010. Structure and function of immunoglobulins. J. Allergy Clin. Immunol. 125:S41-S52.

Srinivasan, A., Y. Ni, and I. Tizard. 1999. Specifity and prevalence of natural bovine antimannan antibodies. Clin. Diagn. Lab. Immunol. 6:946-952.

Star, L., K. Frankena, B. Kemp, M. G. B. Nieuwland, and H. K. Parmentier. 2007. Natural humoral immune competence and survival in layers. Poult. Sci. 86:1090-1099.
Sun, Y., H. K. Parmentier, K. Frankena, and J. J. van der Poel. 2011. Natural antibodies isotypes as predictors of survival in laving hens. Poult. Sci. 90:2263-2274.

Thompson-Crispi, K. A., F. Miglior, and B. A. Mallard. 2013. Genetic parameters for natural antibodies and associations with specific antibody and mastitis in Canadian Holsteins. J. Dairy Sci. 96:3965-3972.

Thornton, B. P., V. Vetvicka, and G. D. Ross. 1994. Natural antibody and complement-mediated antigen processing and presentation by B lymphocytes. J. Immunol. 152:1727-1737.

van Knegsel, A. T. M., G. de Vries Reilingh, S. Meulenberg, H. van den Brand, J. Dijkstra, B. Kemp, and H. K. Parmentier. 2007. Natural antibodies related to energy balance in early lactation dairy cows. J. Dairy Sci. 90:5490-5498.

Wijga, S., H. Bovenhuis, J. W. M. Bastiaansen, J. A. M. van Arendonk, T. C. W. Ploegaert, E. Tijhaar, and J. J. van Poel. 2013 Genetic parameters for natural antibody isotype titers in milk of Dutch Holstein-Friesians. Anim. Genet. 44:485-492. 